\title{
Extended Spectrum Beta-lactamases: Definition, Classification and Epidemiology
}

\author{
Sobhan Ghafourian, ${ }^{* 1,2}$ Nourkhoda Sadeghifard, ${ }^{1}$ \\ Sara Soheili, ${ }^{2}$ Zamberi Sekawi*2 \\ ${ }^{1}$ Clinical Microbiology Research Center, Ilam University of \\ Medical Sciences, Ilam, Iran \\ 2Department of Medical Microbiology and parasitology, \\ Faculty of Medicine and Health Sciences, Universiti Putra \\ Malaysia, Malaysia \\ *Corresponding authors: sobhan.ghafurian@gmail.com; \\ zamberi@medic.upm.edu.my \\ DOI: http://dx.doi.org/10.21775/cimb.017.011
}

\begin{abstract}
Extended spectrum beta-lactamases (ESBLs) are defined as enzymes produced by certain bacteria that are able to hydrolyze extended spectrum cephalosporin. They are therefore effective against beta-lactam antibiotics such as ceftazidime, ceftriaxone, cefotaxime and oxyiminomonobactam. The objective of the current review is to provide a better understanding of ESBL and the epidemiology of ESBL producing organisms which are among those responsible for antibiotic resistant strains. Globally, ESBLs are considered to be problematic, particularly in hospitalized patients. There is an increasing frequency of ESBL in different parts of the world. The high risk patients are those contaminated with ESBL producer strains as it renders treatment to be ineffective in these patients. Thus, there an immediate needs to identify EBSL and formulate strategic policy initiatives to reduce their prevalence.
\end{abstract}

\section{Introduction}

Extended spectrum beta-lactamases (ESBLs) are defined as enzymes produced by certain bacteria that are able to hydrolyze extended spectrum cephalosporin. They are therefore effective against beta-lactam antibiotics like ceftazidime, ceftriaxone, cefotaxime and oxyiminomonobactam (Bradford, 2001; Paterson and Bonomo, 2005). Carbapenems and cephamycine are effective against ESBL producer strains. Generally, ESBLs are inhibited by clavulanic acid and tazobactam. ESBLs are found in Gram-negative bacteria, especially in enterobacteriacea and Pseudomonas aeruginosa (Bradford, 2001; Nordmann and Guibert, 1998). The most important beta-lactamase that is prevalent is TEM-1. It is estimated that more than $90 \%$ of ampicillin resistance among E.coli is related to the presence of TEM-1 (Livermore, 1995). TEM-1 is able to hydrolyze penicillin and first generation cephalosporins. The first derivative of TEM-1 is TEM-2, with a single replacement of amino acids (Du Bois et al., 1995). The difference between beta- lactamase enzymes is the substitution of amino acids that produces different phenotype of enzymes. Another prevalent type of beta- lactamases is SHV-1, which was described initially in $K$. pneumoniae. It is estimated that SHV-1 is responsible for plasmid mediated ampicillin resistance in bacteria which harbors it. The replacement of amino acids causes the change in enzyme structures and its activities (Bradford, 2001). The substitutions are more common among TEM, SHV and OXA enzymes in defined amino acids positions. The combination of altered amino acids produces different phenotypes of beta-lactamase enzymes with varying ability to hydrolyze $3^{\text {rd }}$ generation cephalosporin and increases the level of resistance to beta-lactamase inhibitors (Winokur et al., 2000). It is observed that the use of different oxamino -beta -lactam antibiotics as well as $1^{\text {st }}$ generation cephalosporin and penicillin have caused changes in ESBLs (Blazquez et al., 2000). As the use of beta- lactams antibiotics was excessive, the ESBLs producer strains were selected. These strains produce different phenotypes and effect changes in porins such as Omp (Shakib et al., 2012) to develop resistance to cephamycins and other antimicrobials (Bradford et al., 1994). The plasmids are responsible for ESBL production and also contain other genes that show resistance to aminoglycoside and cotrimoxazole (Villa et al., 2000). Studies revealed that Quinolone resistance is more prevalent in strains that produce ESBL although, the mechanism of co-resistance is not clear (Paterson et al., 2000). ESBLs are currently very important in the medical field. This is because they are able to make the strains resistant to cephalosporins, the workhorse hospital antibiotics applied for many illnesses as first line antibiotics. Any delay in identification and failure to treat the severe infections caused by ESBL producers would result in increasing morbidity and mortality. As ESBL producer strains often show multidrug resistance, such as resistance to amino glycosides and fluoroquinolones, the therapeutic options associated with these strains are limited. It is thus obvious that there is an increasing prevalence of ESBLs producers and the ESBLs producer strains are causing higher levels of morbidity, mortality, and health care-associated costs.

The objective of the current review is to obtain a better understanding of ESBL and the epidemiology of ESBL producer organisms which are also responsible for antibiotic resistance strains.

\section{Classification of beta-lactamases}

There is a different scheme for classification of betalactamases, the most famous was developed by Bush, Jacoby and Medeiros (Bush et al., 1995). This scheme is 
Table 1. Classification of beta-lactamases

\begin{tabular}{|c|c|c|c|}
\hline $\begin{array}{l}\text { Ambler } \\
\text { Class }\end{array}$ & $\begin{array}{l}\text { Bush } \\
\text { Group }\end{array}$ & Characteristics of beta-lactamases & $\begin{array}{l}\text { Number } \\
\text { of } \\
\text { enzymes }\end{array}$ \\
\hline C & 1 & $\begin{array}{l}\text { Often chromosomal enzymes in gram-negatives but some are } \\
\text { Plasmid-coded. Not inhibited by clavulanic acid. }\end{array}$ & 51 \\
\hline \multirow[t]{8}{*}{ A } & $2 a$ & Staphylococcal and enterococcal penicillinases & 23 \\
\hline & $2 \mathrm{~b}$ & $\begin{array}{l}\text { Broad spectrum betalactamases including TEM-1 and SHV-1, mainly } \\
\text { occurring in gram-negatives }\end{array}$ & 16 \\
\hline & $2 \mathrm{be}$ & Extended spectrum betalactamases (ESBL) & 200 \\
\hline & $2 \mathrm{br}$ & Inhibitor-resistant TEM (IRT) betalactamases & 24 \\
\hline & $2 c$ & Carbenicillin-hydrolysing enzymes & 19 \\
\hline & $2 d$ & Cloxacillin (oxacillin) hydrolysing enzymes & 31 \\
\hline & $2 e$ & Cephalosporinases inhibited by clavulanic acid & 20 \\
\hline & $2 f$ & Carbapenem-hydrolysing enzyme inhibited by clavulanic acid & 4 \\
\hline B & 3 & $\begin{array}{l}\text { Metallo-enzymes that hydrolyse carbapenems and other betalactams } \\
\text { except monobactams. Not inhibited by clavulanic acid }\end{array}$ & 24 \\
\hline D & 4 & Miscellaneous enzymes that do not fit into other groups & 9 \\
\hline
\end{tabular}

based on the molecular structure and earlier schemes. According to the Bush, Jacoby and Medeiros scheme, beta-lactamases are divided into four groups as shown in Table 1. The first scheme, introduced by Ambler (Ambler et al., 1991), which is also widely used, is shown in table 1 as well.

\section{Group I (Ambler Class C) beta-lactamases (also known as} AmpC enzymes).

This group is resistant to beta- lactamase inhibitors like clavolunate and mostly is found on chromosomes (Minami et al., 1980). In this class, the enzyme is inducible. Thus any exposure of bacteria to beta-lactame antibiotics leads to an increase in enzyme production. As beta-lactam antibiotics are different, they are able to stimulate different levels of beta-lactamase production. The enzymes in group $I$ are found in the Enterobacteriacea family as well as $P$. aeruginosa. Studies have also shown the shift of enzymes from chromosome to plasmid in some strains such as E.coli and Klebsiella spp (Sanders and Sanders, 1992). The Group I producer beta-lactamases are resistant to beta lactam/beta-lactamase inhibitor combinations, penicillins, cephamycins, as well as 1st, 2nd and 3rd generation cephalosporins. They are sensitive to cefepime and carbapenems (Sanders et al., 1996).

\section{Group 2 (Ambler Class A) enzymes}

As the enzymes classified into group 2 are harbored by plasmid, they could easily be transmitted into different bacterial cells, causing rapid resistance to such enzymes. The beta-lactamase inhibitors such as clavulanic acid, sulbactam and tazobactam inhibit the original group 2 enzymes. The main group 2 enzymes are TEM and SHV. TEM-1 was first identified in 1965 in the Enterobacteriacea family. Then it spread to bacteria such as Haemophilus, Neisseria, and Vibrio spp. SHV-1 was discovered in 1979 
and is commonly found in Klebsiella spp and E. coli (De Champs et al., 1991). Group 2 enzymes could hydrolyze ampicillin and $1^{\text {st }}, 2^{\text {nd }}$ and $3^{\text {rd }}$ generation cephalosporins as well as monobactams (the extended spectrum betalactamases or ESBLs) and they are resistant to betalactamase (Livermore, 1995).

\section{Group 3 (Ambler Class B) enzymes}

These are metallo-enzymes capable of destroying carbapenems (Burn-Buisson et al., 1987).These enzymes are frequently found in $P$. aeruginosa, Bacteroides fragilis and Stenotrophomonas maltophilia.

\section{Group 4 beta-lactamases}

Group 4 beta-lactamases contains those unusual penicillinases not inhibited by clavulanic acid. Four of these enzymes exhibit high rates of hydrolysis with carbenicillin and/or cloxacillin. Several exhibit unusual behavior with respect to metal ion involvement. Whether these enzymes represent another molecular class of beta-lactamase is not known.

\section{Types of ESBLs}

The types of ESBLs that are important are as follows:
TEM - beta - lactamases

The TEM-type ESBL are derivatives from TEM-1 and TEM-2 (Figure 1). TEM-3 was first discovered in $K$. pneumoniae in France in 1984. Initially it was known as CTX-1, because of its activity against cefotaxime (BurnBuisson et al., 1987).Now it is called TEM-3, which is different from TEM-2, which is a replacement of two amino acids (Sougakoff et al., 1987). The numbers of TEM type beta-lactamses currently exceed 100 . All of them, with the exception of TEM-1 and TEM-2, are ESBLs. The most common TEM type ESBL is found in E.coli and K.pneumoniae. However, they could appear in the other Gram-negative bacteria (Livermore, 1995) and also in different genera of Enterobacteriaceae (Enterobacter aerogenes, Enterobacter cloacae, Morganella morganii, Proteus mirabilis and Salmonella spp) (Morosini et al., 1995; Marchandin et al., 1999). In Non-Enterobacteriaceae, they are in $P$. aeruginosa (Nordmann and Guibert, 1998).

\section{SHV - beta - lactamases}

The SHV is more prevalent than the other types of ESBLs in clinical isolates of bacteria (Jacoby, 1997). Unlike the TEM-type beta-lactamases, fewer SHV type beta-
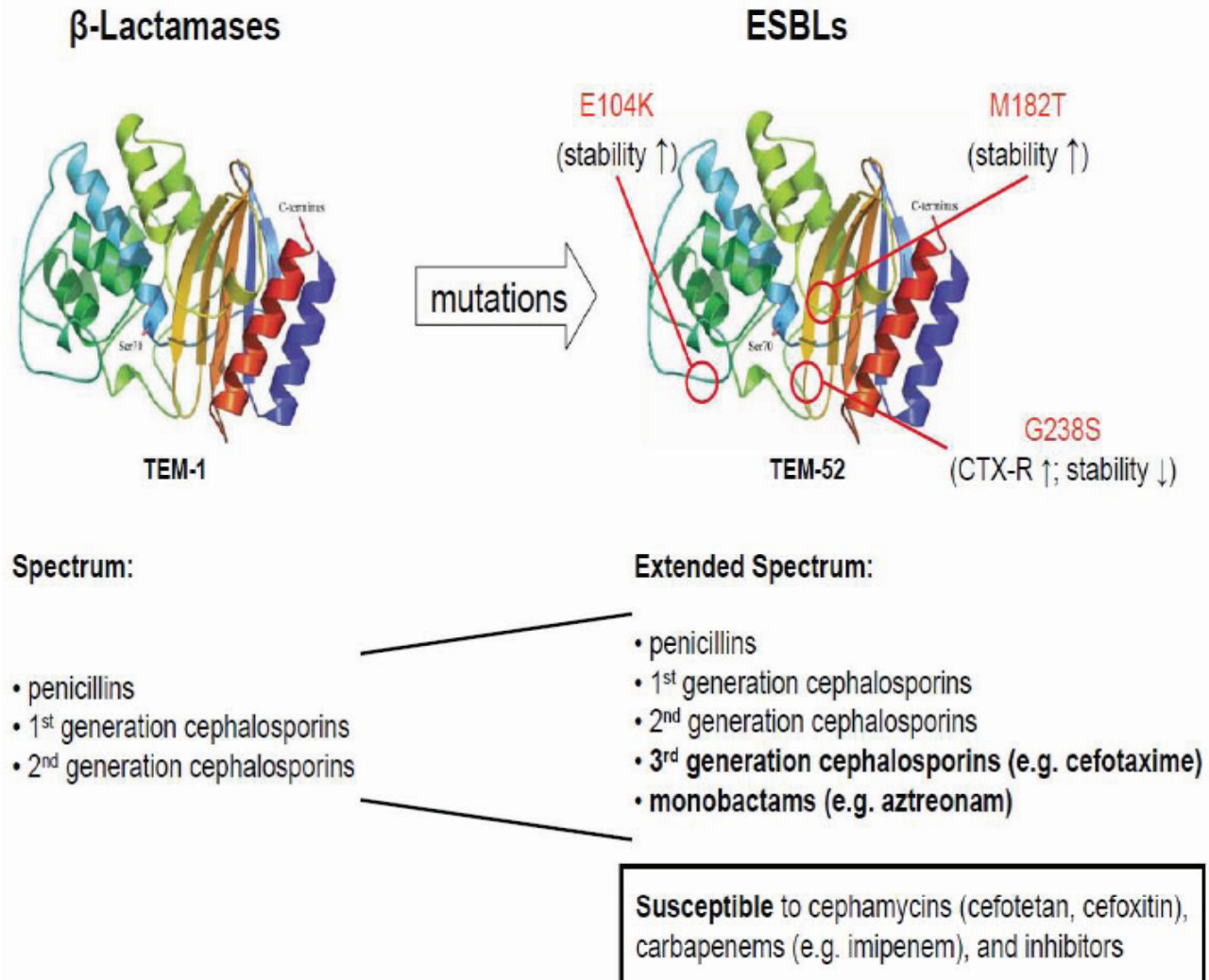

Figure 1. Amino acid substitution of TEM-1 and make new TEM-52. 
lactamase are derived from SHV-1. Most strains have SHV on their plasmid through the replacement of serine to glycine at position 238. In addition, some strains change lysine to glutamate at position 240 . The serine residue at position 238 is essential for hydrolyzing ceftazidime and the lysine residue is critical for hydrolyzing cefotaxime. More than $100 \mathrm{SHV}$ varieties are known worldwide currently. SHV-type of ESBLs are found in a wide range of Enterobacteriaceae (Harrif-Heraud et al., 1997) P.aeruginosa and Acinetobacter spp (Huang et al., 2004; Poirel et al., 2004).

\section{CTX - $M$ beta - lactamases}

CTX-M was first described by Tzouvelekis in 2000 (Tzouvelekis et al., 2000). The term CTX-M beta-lactamase denotes its ability to cefotaxime (Bonnet, 2004). CTX-M is able to hydrolyze cephalothin better than benzyl-penicillin and cefotaxime better than ceftazidime. On the other hand, though the MIC analysis of bacteria for resistance to ceftazidime was carried out, some of the CTX-M- type beta-lactamases showed resistance to this drug (Poirel et al., 2002). Further, the resistance to Aztreonam was having been identified to be variable. CTX-M-type betalactamases are able to hydrolyze cefipime (Tzouvelekis et al., 2000). They inhibit better with beta-lactamase inhibitor tazobactam than sulbactam and clavulanate (Bush et al., 1993). Unlike TEM and SHV enzymes, there is no point mutation in CTX-M and it is believed that CTX-M was first identified from the chromosome Kluyvera spp following its transforming to plasmid (Radice et al., 2002). Thus far, 128 types of CTX-M have been reported and are classified into five classes as follows: CTX-M-1, CTX-M-2, CTX-M-8, CTX-M-9 and CTX-M-25. They are found in different Enterobacteriaceae, including Salmonella spp (Bradford et al., 1998).

\section{Epidemiology of ESBLs}

The epidemiology of ESBL in different parts of the world is different (Figures 2, 3). Some of the epidemiology studies are as follows:

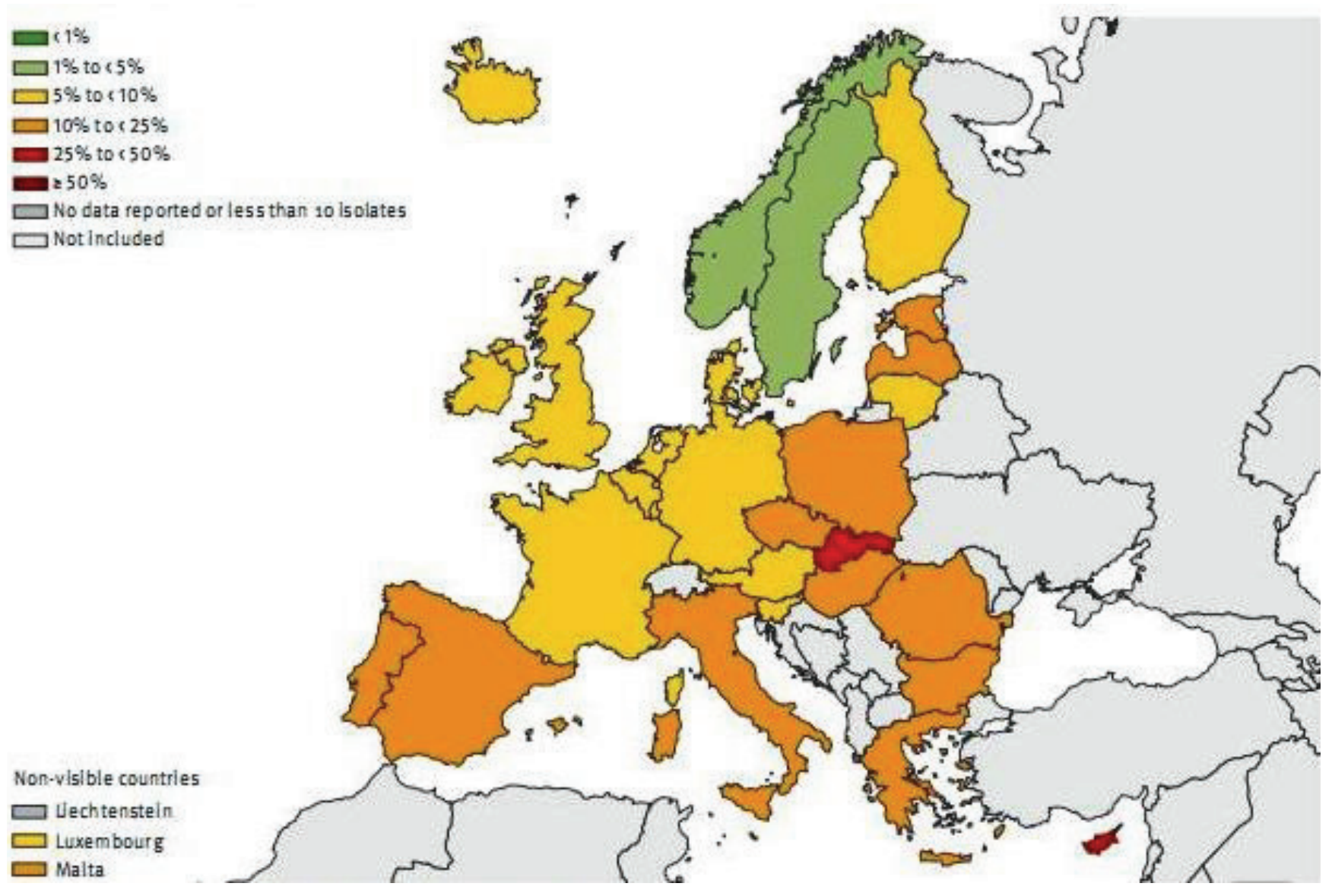

Figure 2. E. coli: percentage (\%) of invasive isolates resistant to third-generation cephalosporins, EU/EEA, 2011. 


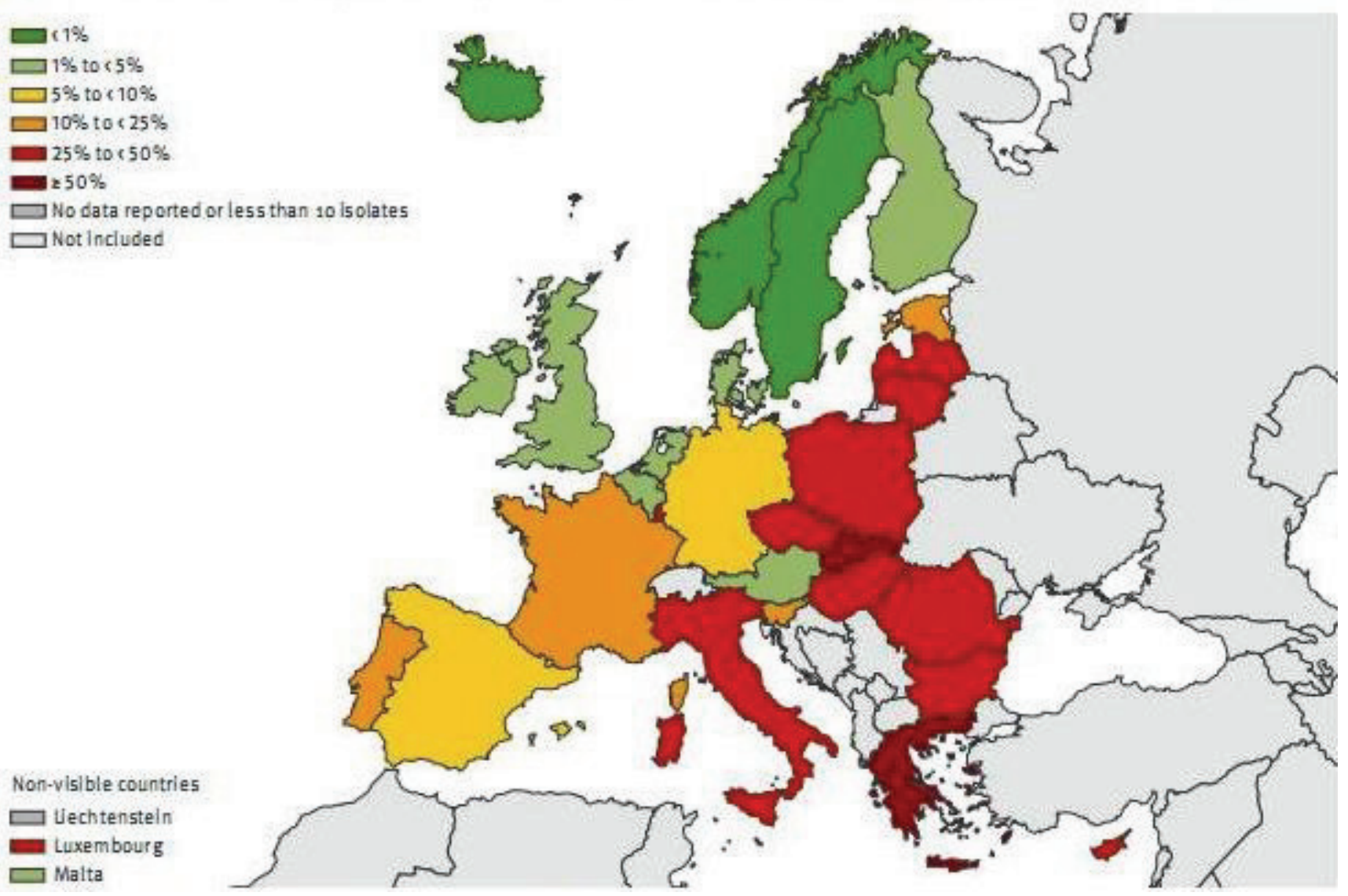

Figure 3. K. pneumoniae: percentage (\%) of invasive isolates resistant to third-generation cephalosporins, EU/EEA, 2011.

\section{Europe}

The first report of ESBL producer strains was from Europe, specifically Germany (Knothe et al., 1983) and England (Du Bois et al., 1995). Subsequently, the vast majority of ESBL positive strains were found in France (Philippon et al., 1989). The first occurrence of ESBL in France was in 1986, where of 54 patients from three intensive care units (ICUs) were found positive for ESBL (Burn-Buisson et al., 1987). In the decade of the 1990 s, about 25 to $35 \%$ of nosocomial infections by $K$. pneumoniae isolates in France were found positive for ESBL (Marty and Jarlier, 1998). In recent times, the frequency of ESBL among Enterobacteriaceae in France was under 1\%, while there were an increasing prevalence of CTX-M (Galas et al., 2008). The studies also showed that the prevalence of ESBL producer strains in 2005 was much lower than in previous years, for instance $P$. mirabilis $3.7 \%$ decreasing to $1.3 \%)$, Enterobacter aerogenes (53.5\% decreasing to $21.4 \%$ ) and $K$. pneumoniae (9.4\% decreasing to $3.71 \%)$. However, there was an increase in E. coli ESBL producer from $0.2 \%$ to $2 \%$ (Arpin et al., 2007). According to a national surveillance report, there was an increase in ESBL producer strains in northern European countries such as Denmark, Norway and Sweden. The studies also showed prevalence of ESBL positive strains in Spain and Portugal.
Further increasing prevalence of CTX-M among patients with urinary tract infections (Oteo et al., 2006; Machado et al., 2007) were observed. In the last ten years, Italy also showed an increase in ESBL positive strains (Luzzaro et al., 2006). The frequency of the occurrence of ESBL positive strains was more than $10 \%$ in Eastern Europe countries such as Hungary, Poland, Romania, Russia and Turkey. In all the mentioned countries, K. pneumoniae was found to be dominant ESBL positive (Damjanova et al., 2007; Korten et al., 2007; Markovska et al., 2008 ). The enzymes mostly responsible for ESBL production in Eastern Europe countries are: CTX-M-3, SHV-2 and SHV-5. It is evident that there is an increasing prevalence of CTX-M-15 and it constitutes the epidemiology of ESBL in all the European countries (Oteo et al., 2006). According to EARSS data for 2011 concerning only invasive isolates (Casellas and Goldberg, 1989), the resistance to thirdgeneration cephalosporins in $E$. coli isolates at that time varied from 3\% in Sweden to $36 \%$ in Cyprus, and showed a clear north- to-south gradient, with the highest percentages of resistance reported from southern Europe and lower percentages reported by countries in northern Europe. Between 2008 and 2011, the percentages of $E$. coli isolates resistant to third-generation cephalosporins significantly increased in 18 of 28 reporting countries. No 
country showed a decreasing trend during this period (Figure 2). The corresponding rates for $K$. pneumoniae ranged from the $2 \%$ noted in Sweden to the incredibly high levels of $81 \%$ in Bulgaria. Trend analyses for the period 2008 to 2011 showed significantly increasing trends for 10 of 25 reporting countries, while none of the countries showed a decreasing trend. The percentages of thirdgeneration cephalosporin-resistant isolates reported as ESBL- positive ranged between $65 \%$ and $100 \%$ (Figure 3 ) (EARSS, 2011).

\section{South and Central America}

SHV-2 and SHV-5 were first reported to harbor $K$. pneumoniae during the period 1988 to 1989 in Chile and Argentina (EARSS, 2011). The studies revealed that ESBLs positive were identified in 30 to $60 \%$ of Klebsiella spp in Brazil, Colombia, and Venezuela (Mendes et al., $2000)$. The prevalence of ESBL producer $E$. coli and Klebsiella in Latin America showed an increase in 2008 compared to the previous years. Generally, $26 \%$ of $E$. coli and $35 \%$ of $K$. pneumoniae in Latin American were ESBL producers in 2008. In 2003, $10 \%$ of $E$. coli and $14 \%$ of $K$. pneumoniae were positive for ESBL production, while in 2004 , it was $10 \%$ of $E$. coli and $18 \%$ of $K$. pneumoniae (Rossi et al., 2006).

\section{North America}

The first ESBL positive reported in 1988 in the United States, was K. pneumoniae with TEM-10 (Jacoby et al., 1988). This was followed by TEM-12 and TEM -26 (Bush, 2008). In 2001, it was reported that $5.6 \%$ of strains were ESBL positive in the United States (Winokur et al., 2001). In 2009 , a survey on $E$. coli reported that $9 \%$ of $E$. coli were ESBL producers (Bhusal et al., 2011). Further, there were also reports of outbreaks of SHV type ESBLs. Sanchez et al. (Sanchez et al., 2010) investigated data obtained from The Surveillance Network (TSN) concerning in vitro antimicrobial resistance in US outpatients between 2000 and 2010, and their results showed that resistance to ceftriaxone rose from $0.2 \%$ to $2.3 \%$ and resistance to cefuroxime increased from $1.5 \%$ to $5 \%$, but the bacterial isolates in focus were not tested for ESBLs.

\section{Africa}

There have been some studies which showed a high prevalence of ESBL producing $K$. pneumoniae in South Africa (Cotton et al.,2000). A survey conducted during a one year period, between 1998 to 1999 , in a South African hospital indicated that $36.1 \%$ of $K$. pneumoniae were ESBL producers (Bell et al., 2002).

Unfortunately, few investigations have been conducted in sub-Saharan Africa, and they have provided very little data (Aibinu et al., 2003; Kariuki et al., 2007). The first study of ESBLs in Tanzania was performed in 2001-2002 and analyzed blood isolates from neonates, and it was found that $25 \%$ of the $E$. coli and $17 \%$ of the $K$. pneumoniae produced ESBLs, mainly the CTX-M-15 and TEM-63 types (Blomberg et al., 2005). In a more recent investigation conducted at a tertiary hospital in Mwanza, Tanzania, the overall prevalence of ESBLs in all Gramnegative bacteria (377 clinical isolates) was $29 \%$. The ESBL prevalence was $64 \%$ in K. pneumoniae but $24 \%$ in $E$. coli (Kariuki et al., 2007). Dramatic figures were also obtained in a small study at an orphanage in Mali, where $63 \%$ of the adults and $100 \%$ of the children were found to carry ESBL-producing Enterobacteriaceae that showed extensive co-resistance to other antibiotics (Tande et al., 2009). Furthermore, in Madagascar, Herindrainy et al. (Herindrainy et al., 2011) observed that $10 \%$ of nonhospitalized patients carried ESBLs, in the majority of the cases CTX-M-15, and these investigators also found that poverty was a significant risk factor for carriage.

\section{Middle East}

The studies in the Middle East revealed a higher prevalence of ESBL than in others parts of the world. A survey on E. coli ESBL producers in Egypt, conducted during the period 1999 to 2000 , indicated that, $38 \%$ of the E. coli tested positive for ESBLs. In another study in Iran, undertaken between 2007 and 2008, 45\% of the $K$. pneumoniae isolated from urinary tract infections were found to be ESBL producers (Ghafourian et al., 2012). In the same study, it was detected that, $59.2 \%$ of $K$. pneumoniae of the clinical isolates from respiratory tract infections tested positive for ESBL production (Ghafourian et al., 2011). In Iran, a one year study on $E$. coli collected from urinary tract infections showed that $25 \%$ of the isolates were ESBL producers (Pakzad et al., 2011). In 2007 in a study in $\mathrm{K}$. pneumonia demonstrated different range of ESBL production in different cities (Mohebi et al., 2012). In Saudi Arabia, about $26 \%$ of K. pneumniae isolated in 2008 produced ESBLs. In most of the isolates SHV-12, CTX$\mathrm{M}-15$ and TEM-1 were responsible for resistance to $3^{\text {rd }}$ generation cephalosporin (Tawfik et al., 2011). ESBLs were also detected in some North African countries (AitMhand et al., 2002). Moubareck and colleagues (Moubareck et al., 2005) analysed faecal samples in Lebanon in 2003 and noted that ESBL carriage differed somewhat between patients $(16 \%)$, healthcare workers $(3 \%)$, and healthy subjects $(2 \%)$, and also that there was a predominance of the CTX-M-15 enzyme (83\%). Other researchers in Lebanon (Khanfar et al., 2009) observed that the proportion of ESBL-producing isolates was significantly larger among inpatients (15.4\%) than in outpatients $(4.5 \%)$. Moreover, data collected over three years in Kuwait showed that the levels of ESBLs were lower in community 25 isolates of $K$. pneumoniae $(17 \%)$ and $E$. coli $(12 \%)$ than in the corresponding hospital isolates $(28 \%$ and $26 \%$, respectively) (Al Benwan et al., 2010).

\section{Australia}

The first report of an ESBL positive strain in Australia was found in Klebsiella spp (gentamicin resistance) in a study done between 1986 and 1988 (Mulgrave, 1990). They later found that SHV was responsible for ESBL production in Klebsiella spp (Mulgrave and Attwood, 1993). In the last decade, ESBL positive strains were also identified in all the regions in Australia. It is estimated that $5 \%$ of isolates in Australia are positive for ESBL production (Bell et al., 2002).

Asia

The first isolates of $K$. pneumoniae harboring SHV-2 were reported from China in 1988 (Rossi et al., 2006). Recently, 
the study of ESBLs in Asia showed a high prevalence among clinical strains. In 2001, the first CTX-M positive strains were reported in New Delhi (Karim et al., 2001). Some studies on limited isolates collected between 1998 and 1999 , showed that $30.7 \%$ of $K$. pneumoniae and $24.5 \%$ of E.coli isolates were ESBL producers (Bell et al., 2002). In China, between 1997-1999, 27\% of $E$. coli and $K$. pneumonia were identified to be ESBL producers (Du et al., 2002 ). It is estimated that 5 to $8 \%$ of $E$. coli isolates from Korea, Japan, Malaysia, and Singapore were positive for ESBL while it was 12 to $24 \%$ in Thailand, Taiwan, the Philippines, and Indonesia. However, the K. pneumoniae ESBL producers were less than 5\% (Lewis et al., 1999) while in other Asian countries it was between 20 to $50 \%$. There are variations between different hospitals. It has been reported that $1 / 4$ of all the $K$. pneumoniae collected from various hospitals in Japan between 1998 to 1999 tested positive for ESBL production (Bell et al., 2002). The predilection of ESBLs for $K$. pneumoniae has never been clearly explained. It should be noted that the parent enzyme of TEM-type ESBLs, that is TEM-1, is widespread in many other species. Almost all the non-ESBL-producing $K$. pneumoniae isolates have chromosomally mediated SHV-1 beta-lactamases (Babini and Livermore, 2000). As early as the mid 1990s, it was noted that $25 \%$ of the Enterobacteriaceae in Thailand were producing ESBLs, mainly different SHV enzymes (Hawkey, 2008). Luvsansharav et al. (Luvsansharav et al., 2012) analyzed stool samples from healthy volunteers in Thailand in 2009, and the results showed that $30-50 \%$ of these subjects in three different regions were ESBL carriers (CTX-M types). The first report of CTX-M-producing Enterobacteriaceae in New Delhi was published in 2001 (Karim et al., 2001). Later, in 2006, Ensor et al. (Ensor et al., 2006) found that $66 \%$ of third-generation cephalosporin-resistant $E$. coli and $K$. pneumoniae from three medical centers in India harbored the CTX-M-15 type of ESBL, which was also the only CTX-M enzyme found, and an investigation of 10 other centers in that country showed that rates of ESBLproducing Enterobacteriaceae reached $70 \%$ (Mathai et al, 2002). In other recent studies, Sankar et al. (Sankar et al., 2012) observed ESBL rates of $46 \%$ and $50 \%$ in out- and inpatients, respectively, and Nasa and co-workers (Nasa et al., 2012) detected ESBL production in almost $80 \%$ of clinical isolates. Investigations from India and Pakistan shows an alarming and rapid increase in the prevalence of Enterobacteriaceae with NDM-1 with prevalence rate from $6.9 \%$ in a hospital in Varanasi, India, to $18.5 \%$ in Rawalpindi, Pakistan (Nordmann et al., 2011) and perhaps the spread of these enzyme could be even more rapid than the spread of the CTX-M enzymes.

\section{Risk Factors for Colonization and Infection with ESBL Producers}

Many surveys were undertaken to design case control for identification of risk factors for colonization and infection with ESBL producer strains (Ariffin et al., 2000). An analysis of the findings of these surveys reveal a plethora of conflicting results, especially in terms of the differences in the investigated population, case study, controls, and sample sizes (Paterson, 2002). Nevertheless, some generalizations could be made. The high-risk patients contaminated with ESBL are those who have severe illnesses and prolonged hospitalization. The median length of hospitalization prior to collection of positive strain for ESBL production range between 11 to 67 days. Use of large quantities of antibiotics is also a risk factor for ESBL production (Ariffin et al., 2000). Furthermore, a strong correlation was evident between using ceftazidime and the frequency of ceftazidime-resistant strains in the wards of the same hospital. In a survey of 15 hospitals, an association was detected between cephalosporin and aztreonam usage as well as an isolation rate of ESBL positive strains. Using different classes of antibiotics also resulted in infections due to ESBL positive strains. These include quinolones, cotrimoxazol, aminoglycosides, and metronidazole. However, no association was noted between use of beta-lactam/beta-lactamase inhibitor combinations, penicillins, or carbapenems and the presence of ESBL positive strains. Transmission of such bacteria usually occurs via the faecal- oral route, either directly or indirectly through hand contact with healthcare workers, and it is facilitated by overcrowding. Historically, K. pneumoniae and treatment in ICUs are associated with many of the risk factors, which include various medical devices such as central and arterial access lines, and nasogastric and endotracheal tubes. Other risk factors mentioned in the literature are prolonged hospital stays, living in nursing homes or long-term care facilities, underlying medical conditions, recent surgery, haemodialysis, and also prior use of antibiotics, particularly quinolones and third-generation cephalosporins, but also co-trimoxazole, aminoglycoside, and metronidazole (Lytsy et al., 2008; Pitout and Laupland, 2008). However, the positive predictive value of these risk factors is low (Ruppe et al., 2012). Plasmids encoding quinolone-resistant ESBLs and other ESBLs in general have been identified around the world, and the association between the use of quinolones and development of ESBLs is often referred to as "collateral damage" that is an adverse ecological effect of antibiotics (Paterson et al., 2000; Robicsek et al., 2006). Compared to $E$. coli, it is often assumed that Klebsiella is more successful in disseminating, and the latter bacteria are now the most abundant. In a study by Harris et al. (Harris et al., 2007), it seemed that, despite a larger reservoir of $E$. coli at ICU admission, there was more extensive transmission of $K$. pneumoniae. Over the past few years the researchers (Tham et al., 2010) have found evidence that international travel to highly endemic areas (i.e., Asia, the Middle East, and Africa) represents one of the most important risk factors for ESBL carriage especially in the community.

\section{Conclusion}

ESBLs are known to cause problems in patients who are especially hospitalized. There have been reports of an increasing prevalence of ESBLs in different regions of the world. The high risk patients are known to be those who are contaminated with ESBL producer strains as this renders treatments to be ineffective on them. Thus there is an urgent need for immediate identification and appropriate policy directions to reduce the prevalence of ESBLs. In dealing with the infected patient, priority must be given to 
appropriate and effective antimicrobials, good hand hygiene, and avoiding unnecessary procedures, including central venous catheters. On an institutional level, screening and isolating all such infected patients with appropriate infection control practices, restricting use of broad spectrum cephalosporins across the hospital (implementing a stricter antimicrobial policy) and investigating environmental contamination are important. here is no doubt that ESBL-producing infections are of grave concern to the medical world. They are associated with an increased morbidity and mortality and can be difficult and time consuming to identify. Coupled with the fact that prevalence rates are rising globally, including in nonhospital settings, and the dire lack of effectiveness antimicrobial therapy, the future is tremendously concerning. Urgent work is required to develop quicker, cost-effective, and reliable diagnostic tools as well as new effective therapies.

\section{References}

Aibinu, I. E., Ohaegbulam, V. C., Adenipekun, E. A., Ogunsola, F. T., Odugbemi, T. O., and Mee, B. J. (2003) Extended-spectrum beta-lactamase enzymes in clinical isolates of Enterobacter species from Lagos, Nigeria. J Clin Microbiol, 41 (5), 2197-200.

AitMhand, R., Soukri, A., Moustaoui, N., Amarouch, H., EIMdaghri, H., Sirot, D., and Benbachir, M. (2002). Plasmid-mediated TEM-3 extended-spectrum betalactamase production in Salmonella typhimuium in Casablanca. J Antimicrob Chemother, 49, 169-172.

Al Benwan, K., Al Sweih, N., and Rotimi, V. O. (2010). Etiology and antibiotic susceptibility patterns of community- and hospital-acquired urinary tract infections in a general hospital in Kuwait. Med Princ Pract, 19 (6), 440-446.

Ambler, R.P., Coulson, A.F., Frere., J.M., Ghuysen, J. M., Joris, B., Forsman, M., Levesque, R.C., Tiraby, G., and Waley, S. G. (1991). A standard numbering scheme for the class A beta-lactamases [letter]. Biochemical Journal, 276 (Pt 1), 269-70.

Ariffin, H., Navaratnam, P., Mohamed, M., Arasu, A., Abdullah, A. W., Lee, C. L., and Peng, L. H. (2000). Ceftazidime-resistant Klebsiella pneumoniae bloodstream infection in children with febrile neutropenia. Int $\mathrm{J}$ Infect Dis, 4, 21-25.

Arpin, C., Coulange, I., Dubois, V., Andre, C., Fischer, I., Fourmaux, S., Grobost, F., Jullin, J., Dutilh, B., Couture, J. F., Noury, P., Lagrange, I., Ducastaing, A., Doermann, H. P., and Quentin, C. (2007). Extended-spectrum-betalactamase-producing Enterobacteriaceae strains in various types of private health care centers. Antimicrob Agents Chemother, 51(9), 3440-4.

Babini, G. S., and Livermore, D. M. (2000). Antimicrobial resistance amongst Klebsiella spp. collected from intensive care units in Southern and Western Europe in 1997-1998. J Antimicrob Chemother, 45, 183-189.

Bell, J. M., Turnidge, J. D., Gales, A. C., Pfaller, M. A., and Jones, R. N. (2002). Prevalence of extended spectrum beta-lactamase (ESBL)-producing clinical isolates in the Asia-Pacific region and South Africa: regional results from SENTRY Antimicrobial Surveillance Program (1998-99). Diagn Microbiol Infect Dis, 42, 193-198.

Bhusal, Y., Mihu, C. N., Tarrand, J. J., and Rolston, K.V. (2011). Incidence of fluoroquinolone-resistant and extended-spectrum beta-lactamase-producing Escherichia coli at a comprehensive cancer center in the United States. Chemotherapy, 57 (4), 335-8.

Blazquez, J., Morosini, M.I., Negri M.C., and Baquero, F. (2000). Selection of naturally occuring extendedspectrum TEM ß-lactamase variants by fluctuating ßlactam pressure. Antimicrob Agents Chemother; 44, 2182-2184.

Blomberg, B., Jureen, R., Manji, K. P., Tamim, B. S., Mwakagile, D. S., and Urassa, W. K. (2005). High rate of fatal cases of pediatric septicemia caused by gramnegative bacteria with extended-spectrum betalactamases in Dar es Salaam, Tanzania. J Clin Microbiol, 43 (2),745-9.

Bonnet, R. (2004). Growing group of extended-spectrum betalactamases: the CTX-M enzymes. Antimicrob Agents Chemother, 48, 1-14.

Bradford, P. A., Cherubin, C. E., Idemyor, V., Rasmussen, B. A., and Bush, K. (1994). Multiply resistant Klebsiella pneumoniae from two Chicago hospitals: identification of the extended-spectrum TEM-12 and TEM-10 ceftazidime-hydrolyzing beta-lactamases in a single isolates. Antimicrob Agents Chemother, 38, 761-766.

Bradford, P. A., Yang, Y., Sahm, D., Grope, I., Gardovska, D., and Storch, G. (1998). CTX-M-5, a novel cefotaximehydrolyzing beta-lactamase from an outbreak of Salmonella typhyimurium in Latvia. Antimicrob Agents Chemother; 42, 1980-1984.

Bradford, P.A. (2001). Extended spectrum beta-lactamases in the 21st century: characterization, epidemiology and the detection of this important resistance threat. Clin Microbiol Rev, 14, 933-951.

Bush, K., Macalintal, C., Rasmussen, B. A., Lee, V.J., and Yang,Y. (1993). Kinetic interactions of tazobactam with beta-lactamases from all major structural classes. Antimicrob Agents Chemother, 37, 851-858.

Bush, K., Jacoby, G.A., and Medeiros, A. A. (1995). A functional classification scheme for beta-lactamases and its correlation with molecular structure. Antimicrobial Agents \& Chemotherapy, 39(6), 1211-33.

Bush, K. (2008). Extended-spectrum beta-lactamases in North America, 1987-2006. Clin Microbiol Infect, 14 Suppl 1, 134-43.

Burn-Buisson, C., Legrand, P., Philippon, A., Montravers, F., Asquer, M., and Duval, J. (1987). Transferable enzymatic resistance to third generation cephalosporins during nosocomial outbreak of multiresistant Kelbsiella pneumoniae. Lancet, 11, 302-306.

Casellas, J. M., and Goldberg, M. (1989). Incidence of strains producing extended spectrum beta-lactamases in Argentina. Infection, 17, 434-436.

Cotton, M. F., E. Wasserman, C. H. Pieper, D. C. Theron, D. van Tubbergh, G. Campbell, F., Fang, C., and Barnes, J. (2000). Invasive disease due to extended spectrum beta-lactamase-producing Klebsiella pneumoniae in a neonatal unit: the possible role of cockroaches. J Hosp Infect, 44, 13-17. 
Damjanova, I., Tth, A., Pszti, J., Jakab, M., Milch, H., Bauernfeind, A., and Fuzi, M. (2007). Epidemiology of SHV-type $\beta$-lactamase-producing Klebsiella spp. From outbreaks in five geographically distant Hungarian neonatal intensive care units: widespread dissemination of epidemic R-plasmids. Int J Antimicrob Agents, 29 (6), 665-71.

De Champs, C., Sirot, D., Chanal, C., Poupart, M. C., Dumas, M. P., and Sirot, J. (1991). Concomitant dissemination of three extended-spectrum betalactamases among different Enterobacteriaceae isolated in a French hospital. J. Antimicrob. Chemother, 27, 441-457.

Du Bois, S. K., Marriott, M.S., and Amyes, S.G. (1995). TEM- and SHV- derived extended-spectrum betalactamases: relationship between selection, structure and function. J. Antimicrob. Chemother, 35, 7-22.

Du, B., Long, Y., Liu, H., Chen, D., Liu, D., Xu, Y., and Xie, X. (2002). Extendedspectrum beta-lactamase-producing Escherichia coli and Klebsiella pneumonia bloodstream infection: risk factors and clinical outcome. Intensive Care Med, 28, 1718-1723.

EARSS. http://www.rivm.nl/earss/database/ Accessed 16-09-2011. 2011.

Ensor, V. M., Shahid, M., Evans, J. T., and Hawkey, P. M. (2006). Occurrence, prevalence and genetic environment of CTX-M beta-lactamases in Enterobacteriaceae from Indian hospitals. J Antimicrob Chemother, 58 (6), 1260-3.

Galas, M., Decousser, W. J., Breton, N., Godard, T., Allouch, P. Y., and Pina, P. (2008). Nationwide study of the prevalence, characteristics, and molecular epidemiology of extended-spectrum-beta-lactamaseproducing Enterobacteriaceae in France. Antimicrob Agents Chemother, 52(2), 786-9.

Ghafourian, S., Sekawi, Z., Sadeghifard, N., Mohebi, R., and Neela, V. (2011). The Prevalence of ESBLs Producing Klebsiella pneumoniae Isolates in Some Major Hospitals, Iran. Open Microbiol J, 5, 91-5.

Ghafourian, S., Sekawi, Z., Neela, V., Khosravi, S., Rahbar, M., and Sadeghifard, N. (2012). Incidence of extendedspectrum beta-lactamase-producing Klebsiella pneumoniae in patients with urinary tract infection. Sao Paulo Med J, 130 (1), 37-43.

Harrif-Heraud Z, Arpin, C., Benliman, S., and Quentin, C. (1997). Molecular epidemiology of a nosocomial outbreak due to SHV-4 producing strain of Citrobacter diversus. J Clin Microbiol, 35, 2561-2567.

Harris, A. D., Perencevich, E. N., Johnson, J. K., Paterson, D. L., Morris, J. G., Strauss, S. M. (2007). Patient-topatient transmission is important in extended-spectrum beta-lactamase- producing Klebsiella pneumoniae acquisition. Clin Infect Dis, 15, 45 (10), 1347-50.

Hawkey, P. M. (2008). Prevalence and clonality of extended-spectrum beta-lactamases in Asia. Clin Microbiol Infect, 14 (Supp I),159-65.

Herindrainy, P., Randrianirina, F., Ratovoson R, Ratsima Hariniana, E., Buisson, Y., Genel, N., Decre, D., Arlet, G., Talarmin, A., and Richard, V. (2011). Rectal carriage of extended-spectrum beta-lactamase-producing gramnegative bacilli in community settings in Madagascar. PLoS One, 6 (7), e22738.
Huang, Z. M., Mao, P. H., Chen, Y., Wu, L., and Wu, J. (2004).Study on molecular epidemiology of SHV type beta-lactamase encoding genes of multiple-drugresistant Acinetobacter baumannii. Zhonghua Liu Xing Bing Xue Za Zhi , 25, 425-427.

Jacoby, G. A. (1997). Extended-spectrum beta-lactamases and other enzymes providing resistance to oxyiminobeta-lactams. Infect Dis Clin North Am, 11, 875-887.

Jacoby, G. A., Medeiros, A. A., Brien, T. F. O., Pinto, M. E., and Jiang, H. (1988). Broad-spectrum, transmissible beta-lactamases. $\mathrm{N}$ Engl J Med, 319, 723-724.

Karim, A., Poirel, L., Nagarajan, S., and Nordmann, P. (2001). Plasmid-mediated extended-spectrum betalactamase (CTX-M-3 like) from India and gene association with insertion sequence ISEcp1. FEMS Microbiol Lett, 201 (2), 237-41.

Kariuki, S., Revathi, G., Corkill, J., Kiiru, J., Mwituria, J., and Mirza, N. (2007). Escherichia coli from communityacquired urinary tract infections resistant to fluoroquinolones and extended-spectrum beta-lactams. J Infect Dev Ctries, 1(3), 257-62.

Khanfar, H. S., Bindayna, K. M., Senok, A. C., and Botta, G. A. (2009). Extended spectrum beta-lactamases (ESBL) in Escherichia coli and Klebsiella pneumoniae: trends in the hospital and community settings. J Infect Dev Ctries, 3 (4), 295-9.

Knothe, H., Shah, P., Krcmery, V., Antal, M., and Mitsuhashi, S. (1983). Transferable resistance to cefotaxime, cefoxitin, cefamandole and cefuroxime in clinical isolates of Klebsiella pneumoniae and Serratia marcescens. Infection, 11, 315-317.

Korten, V., Ulusoy, S., Zarakolu, P., Mete, B, and Turkish MYSTIC Study Group. (2007). Antibiotic resistance surveillance over a 4-year period (2000-2003) in Turkey: results of the MYSTIC Program. Diagn Microbiol Infect Dis, 59(4), 453-7.

Lewis, M. T., Yamaguchi, K., Biedenbach, D. J., and Jones, R. N. (1999). In vitro evaluation of cefepime and other broad-spectrum beta-lactams in 22 medical centers in Japan: a phase II trial comparing two annual organism samples. The Japan Antimicrobial Resistance Study Group. Diagn Microbiol Infect Dis, 35, 307-315.

Livermore DM. 1995. Beta-lactamases in laboratory and clinical resistance. Clin Microbiol Rev, 8, 557-584.

Lytsy, B., Sandegren, L., Tano, E., Torell, E., Andersson, D. I., and Melhus, A. (2008). The first major extendedspectrum beta-lactamase outbreak in Scandinavia was caused by clonal spread of a multiresistant Klebsiella pneumoniae producing CTX-M-15. APMIS, 116 (4), 302-8.

Luvsansharav, U. O., Hirai, I., Nakata, A., Imura, K., Yamauchi, K., Niki, M., Komalamisra, C., Kusolsuk, T., and Yamamoto, Y. (2012). Prevalence of and risk factors associated with faecal carriage of CTX-M betalactamase-producing Enterobacteriaceae in rural Thai communities. J Antimicrob Chemother, 67 (7), 1769-74

Luzzaro, F., Mezzatesta, M., Mugnaioli, C., Perilli, M., Stefani, S., Amicosante, G., Rossolini, G. M., and Toniolo, A. 2006. Trends in production of extendedspectrum beta-lactamases among enterobacteria of medical interest: report of the second Italian nationwide survey. J Clin Microbiol, 44(5), 1659-64. 
Machado, E., Coque, T. M., Cantn, R., Novais, A., Sousa, J. C., Baquero, F., and Peixe L. (2007). High diversity of extended-spectrum beta-lactamases among clinical isolates of Enterobacteriaceae from Portugal. J Antimicrob Chemother, 60 (6), 1370-4.

Marchandin, H., Carriere, C., Sirot, D., Jean-Pierre, H., and Darbas, H. (1999). TEM-24 produced by four different species of Enterobacteriaceae, including Providencia rettgeri, in a single patient. Antimicrob Agents Chemother, 43, 2069-2073.

Markovska, R., Schneider, I., Keuleyan, E., Sredkova, M., Ivanova, D., Markova, B., Lazarova, G., Dragijeva, E., Savov, E., Haydouchka, I., Hadjieva, N., Setchanova, L., Mitov, I., and Bauernfeind, A. (2008). Extendedspectrum beta-lactamase-producing Enterobacteriaceae in Bulgarian hospitals. Microb Drug Resist, 14 (2), 119-28.

Marty, L., and Jarlier, V. (1998). Surveillance of multiresistant bacteria: justification, role of the laboratory, indicators, and recent French data. Pathol. Biol, 46, 217226.

Mathai, D., Rhomberg, P. R., Biedenbach, D. J., and Jones, R. N. (2002). Evaluation of the in vitro activity of six broad-spectrum beta-lactam antimicrobial agents tested against recent clinical isolates from India: a survey of ten medical center laboratories. Diagn Microbiol Infect Dis, 44 (4), 367-77.

Mendes, C., Hsiung, A., Kiffer, C., Oplustil, C., Sinto, S., Mimica, I., and Zoccoli, C. (2000). Evaluation of the in vitro activity of 9 antimicrobials against bacterial strains isolated from patients in intensive care units in Brazil: MYSTIC Antimicrobial Surveillance Program. Braz J Infect Dis, 4, 236-244.

Minami, S., Yotsuji, A., Inoue, M., and Mitsuhashi, S. (1980). Induction of beta-lactamase by various betalactam antibiotics in Enterobacter cloacae. Antimicrob Agents Chemother, 18(3), 382-5.Mohebi, R., Ghafourian, S., Sekawi, Z., Neela, V., Raftari, M., Aboualigalehdari, E., and Sadeghifard, N. (2012). Extended-spectrum beta-lactamases producing Klebsiella species isolated from several major hospitals in Iran. European Journal of Inflammation, 10 (3), 269-278.

Morosini, M. I., Canton, R., Martinez-Beltran, J., Negri, M. C., Perez-Diaz, J. C., Baquero, F., and Blazquez, J. (1995). New extended-spectrum TEM-type betalactamase from Salmonella enteric subsp. enteria isolated in a nosocomial outbreak . Antimicrob Agents Chemother, 39, 458-461.

Moubareck, C., Daoud, Z., Hakime, N. I., Hamze, M., Mangeney, N., Matta, H, Mokhbat, J. E., Rohban, R., Sarkis, D. K., and Doucet-Populaire, F. (2011). Countrywide spread of community- and hospital-acquired extended-spectrum beta- lactamase (CTX-M-15)producing Enterobacteriaceae in Lebanon. J Clin Microbiol, 43 (7), 3309-13.

Mulgrave, L. (1990). Extended broad-spectrum betalactamases in Australia. Med J Aust, 152, 444-445.

Mulgrave, L., and Attwood, P. V. (1993). Characterization of an SHV-5 related extended broad-spectrum betalactamase in Enterobacteriaceae from Western Australia. Pathology, 25, 71-75.
Nasa, P., Juneja, D., Singh, O., Dang, R., and Singh, A. (2012). An observational study on bloodstream extended-spectrum beta-lactamase infection in critical care unit: incidence, risk actors and its impact on outcome. Eur J Intern Med, 23 (2), 192-5.

Nordmann, P., and Guibert, M. (1998). Extended spectrum beta-lactamases in Pseudomonas aeruginosa. J Antimicrob Chemother, 42:128-131.

Nordmann, P., Poirel, L., Walsh, T. R., and Livermore, D. M. (2011). The emerging NDM carbapenemases. Trends Microbiol, 19 (12), 588-95.

Pakzad, I., Ghafourian, S., Taherikalni, M., Sadeghifard, N., Abtahi, H., Rahbar, M., and Mansory Jamshidi, N. (2011). qnr Prevalence in Extended Spectrum Beta-lactamases (ESBLs) and None-ESBLs Producing Escherichia coli Isolated from Urinary Tract Infections in Central of Iran. Iran J Basic Med Sci, 14 (5), 458-64.

Paterson, D. L., Mulazimoglu, L., Casellas, J.M., Ko, W. C., Goossens, H., Von Gottberg, A., Mohapatra, S., Trenholme, G. M., Klugman, K. P., McCormack, J. G., and Yu, V. L. (2000). Epidemiology of ciprofloxacin resistance and its relationship to extended-spectrum beta-lactamase production in Kelbsiella pneumoniae isolates causing bacteremia. Clin Infect Dis, 30, 473-478.

Paterson, D. L. (2002). Looking for risk factors for the acquisition of antibiotic resistance: a 21st-century approach. Clin Infect Dis, 34, 1564-1567.

Paterson, D.L, and Bonomo, R.A. (2005). Extendedspectrum beta-lactamases: a clinical update. Clin Microbiol Rev, 18, 657-686.

Philippon, A., Labia, R., and Jacoby, G. (1989). Extendedspectrum betalactamases. Antimicrob Agents Chemother; 33, 1131-1136.

Pitout, J. D., and Laupland, K. B. (2008). Extendedspectrum beta-lactamase-producing Enterobacteriaceae: an emerging public-health concern. Lancet Infect Dis, 8 (3), 159-66.

Poirel, L., Gniadkowski, M., and Nordmann, P. (2002). Biochemical analysis of the ceftazidime-hydrolysing extended-spectrum beta-lactamase CTX-M-15 and of its structurally related beta-lactamase CTX-M-3. J Antimicrob Chemother, 50, 1031-1034.

Poirel, L., Lebessi, E., Castro, M., Fevre, C., Foustokou, M., and Nordmann, P. (2004). Nosocomial outbreak of extended-spectrum beta-lactamase SHV-5-producing isolates of Psuedomonas aeruginosa in Athens, Greece. Antimicrob Agents Chemother, 48, 2277-2279.

Oteo, J., Navarro, C., Cercenado, E., Delgado-Iribarren, A., Wilhelmi, I., Orden, B., Garcia, C., Miguelanez, S., Perez-Vazquez, M., Garcia-Cobos, S., Aracil, B., Bautista, V., and Campos, J. (2006). Spread of Escherichia coli strains with high-level cefotaxime and ceftazidime resistance between the community, longterm care facilities, and hospital institutions. J Clin Microbiol, 44(7), 2359-66.

Radice, M., Power, P., DiConza, J., and Gutkind, G. (2002). Early dissemination of CTX-M-derived enzymes in South America. Antimicrob Agents Chemother, 46, 602-604.

Rossi, F., Baquero, F., and Hsueh, P. R. (2006). In vitro susceptibilities of aerobic and facultative Gram-negative bacilli isolated from patients with intra-abdominal infections worldwide: 2004 Study for Monitoring 
Antimicrobial Resistance Trends (SMART). J Antimicrob Chemother, 58, 205-210.

Robicsek, A., Jacoby, G. A., and Hooper, D. C. (2006). The worldwide emergence of plasmid- mediated quinolone resistance. Lancet Infect Dis, 6 (10), 629-40.

Ruppe, E., Pitsch, A., Tubach, F., de Lastours, V., Chau, F., and Pasquet, B. (2012). Clinical predictive values of extended-spectrum beta-lactamase carriage in patients admitted to medical wards. Eur J Clin Microbiol Infect Dis, 31(3):319-25.

Sanchez, G. V., Master, R. N., Karlowsky, J. A., and Bordon, J. M. (2010). In vitro antimicrobial resistance of urinary Escherichia coli isolates among U.S. outpatients from 2000 to 2010. Antimicrob Agents Chemother, 56 (4), 2181-3.

Sanders, C.C, and Sanders, W. E. (1992). Beta-Lactam resistance in gram-negative bacteria: global trends and clinical impact. Clin Infect Dis, 15(5), 824-39.

Sanders, W., Jr, E., Tenney, J. H., and Kessler, R. E. (1996). Efficacy of cefepime in the treatment of infections due to multiply resistant Enterobacter species. Clin Infect Dis, 23(3), 454-61.

Sankar, S., Narayanan, H., Kuppanan, S., and Nandagopal, B. (2012). Frequency of extendedspectrum beta-lactamase (ESBL)-producing Gramnegative bacilli in a 200-bed multi-specialty hospital in Vellore district, Tamil Nadu, India. Infection, 40 (4), 425-9.

Shakib, P., Ghafourian, S., Zolfaghary, M. R., Hushmandfar, R., Ranjbar, R., and Sadeghifard, N. (2012). Prevalence of OmpK35 and OmpK36 porin expression in beta-lactamase and non-betalactamaseproducing Klebsiella pneumoniae. Biologics, 6, 1-4.

Sougakoff W., Goussard, S., Gerbaud, G., and Courvalin, P. (1988). Plasmid-mediated resistance to third generation cephalosporins caused by point mutations in TEM-type penicillinase genes. Rev Infect Dis, 10, 879-884.
Tande, D., Jallot, N., Bougoudogo, F., Montagnon, T., Gouriou, S., and Sizun, J. (2009). Extended- spectrum beta-lactamase-producing Enterobacteriaceae in a Malian orphanage. Emerg Infect Dis, 15 (3), 472-4.

Tawfik, A. F., Alswailem, A. M., Shibl, A. M., and Al-Agamy, M. H. 2011. Prevalence and genetic characteristics of TEM, SHV, and CTX-M in clinical Klebsiella pneumoniae isolates from Saudi Arabia. Microb Drug Resist, 17 (3), 383-8.

Tham, J., Odenholt, I., Walder, M., Brolund, A., Ahl, J., and Melander, E. (2010). Extended-spectrum betalactamase-producing Escherichia coli in patients with travellers' diarrhoea. Scand J Infect Dis, 42 (4), 275-80.

Tzouvelekis, L.S., Tzelepi, E., Tassios, P. T., and Legakis N. J. (2000). CTX-M- type - beta-lactamases: an emerging group of extended spectrum enzymes. Int $\mathrm{J}$ Antimicrob Agents, 14, 137-142.

Villa, L., Pezzella, C., Tosini, F., Visca, P., Petrucca, A., and Carattoli, A. (2000). Multiple-antibiotic resistance mediated by structurally related IncL/M plasmids carrying an extended spectrum beta-lactamase gene and class 1 integron. Antimicrob Agents Chemother, 44, 2911-2914.

Winokur P.L, Brueggemann, D.L. DeSalvo, Hoffmann, L., Apley, M. D., Uhlenhopp, E. K., Pfaller, M.A., and Doern, G. V. (2000). Animal and human multidrug resistant, cephalosporin-resistant Salmonella isolates expressing a plasmid-mediated CMY-2 AmpC betalactamase. Antimicrob Agents Chemother, 44, 2777-2783.

Winokur, P. L., Canton, R., Casellas, J. M., and Legakis, N. (2001). Variations in the prevalence of strains expressing an extended-spectrum beta-lactamase phenotype and characterization of isolates from Europe, the Americas, and the Western Pacific region. Clin Infect Dis, 32 Suppl 2, S94-103. 


\section{Microbiology / Molecular Biology}

Caister Academic Press is a leading academic publisher of advanced texts in microbiology, molecular biology and medical research. Full details of all our publications at caister.com

- Cyanobacteria: Omics and Manipulation Edited by: DA Los (2017) www.caister.com/cyano3

- Brain-eating Amoebae: Biology and Pathogenesis of Naegleria fowleri

Author: R Siddiqui, IKM Ali, JR Cope, et al. (2016)

"explains the current knowledge and research" (ProtoView) www.caister.com/naegleria

- Foot and Mouth Disease Virus: Current Research and Emerging Trends

Edited by: F Sobrino, E Domingo (2017)

www.caister.com/fmdv

- Staphylococcus: Genetics and Physiology

Edited by: GA Somerville (2016)

www.caister.com/staph2

- Chloroplasts: Current Research and Future Trends Edited by: H Kirchhoff (2016)

www.caister.com/chloroplasts

- Microbial Biodegradation: From Omics to Function and Application

Edited by: J Długoński (2016)

www.caister.com/biodegradation

- Influenza: Current Research

Edited by: Q Wang, YJ Tao (2016)

www.caister.com/flu3

- MALDI-TOF Mass Spectrometry in Microbiology Edited by: M Kostrzewa, S Schubert (2016)

www.caister.com/malditof

- Aspergillus and Penicillium in the Post-genomic Era Edited by: RP Vries, IB Gelber, MR Andersen (2016)

"new and well-presented book" (IMA Fungus)

www.caister.com/aspergillus2

- The Bacteriocins: Current Knowledge and Future

Prospects

Edited by: RL Dorit, SM Roy, MA Riley (2016)

www.caister.com/bacteriocins

- Omics in Plant Disease Resistance

Edited by: V Bhadauria (2016)

"essential reading ... highly recommended" (Biotechnol. Agron.

Soc. Environ.)

www.caister.com/opdr

- Acidophiles: Life in Extremely Acidic Environments

Edited by: R Quatrini, DB Johnson (2016)

"Contributors from a wide range of biological and environmental sciences" (ProtoView)

www.caister.com/acidophiles
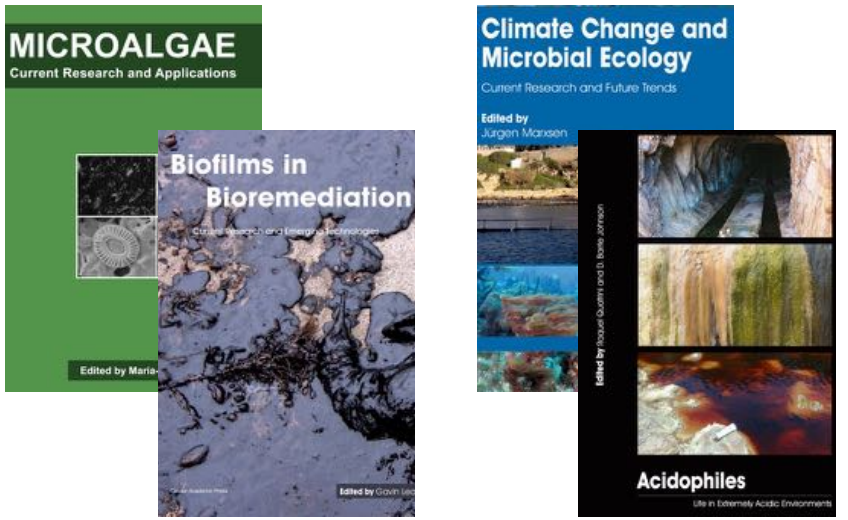
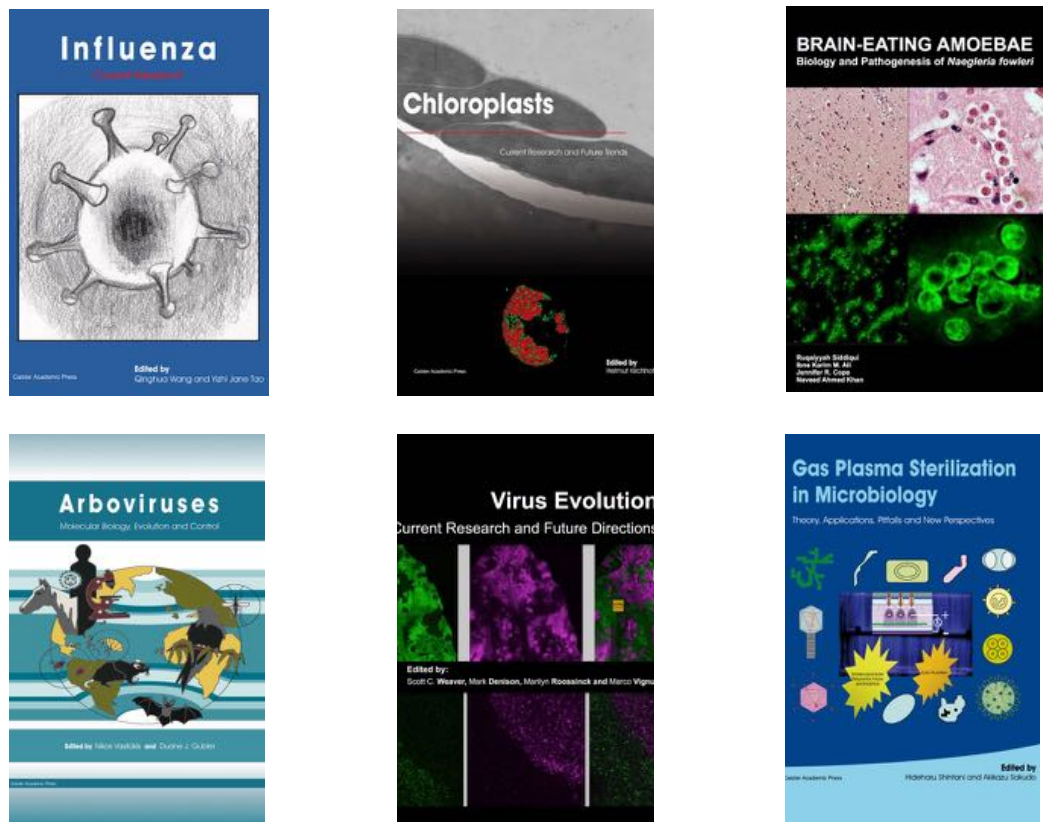

- Climate Change and Microbial Ecology: Current Research and Future Trends

Edited by: J Marxsen (2016)

"impressive" (ASM: Small Things Considered); "written at a high scientific level" (BioSpektrum)

www.caister.com/climate

- Biofilms in Bioremediation: Current Research and Emerging Technologies

Edited by: G Lear (2016)

"describes explicitly the role of biofilms in bioremediation" (Biospektrum); indispensable ... recommended (Biotechnol. Agron. Soc. Environ.) www.caister.com/biorem

- Microalgae: Current Research and Applications

Edited by: MN Tsaloglou (2016)

www.caister.com/microalgae

- Gas Plasma Sterilization in Microbiology: Theory, Applications, Pitfalls and New Perspectives

Edited by: H Shintani, A Sakudo (2016)

"a nice state of the art compilation" (Doodys)

www.caister.com/gasplasma

- Virus Evolution: Current Research and Future Directions Edited by: SC Weaver, M Denison, M Roossinck, et al. (2016) "highly informative ... a pleasure to read" (Microbiol. Today) www.caister.com/virusevol

- Arboviruses: Molecular Biology, Evolution and Control Edited by: N Vasilakis, DJ Gubler (2016)

"a thorough and compelling review ... an outstanding book ... highly recommended" (Am. J. Trop. Med. Hyg.) www.caister.com/arbo

- Shigella: Molecular and Cellular Biology

Edited by: WD Picking, WL Picking (2016)

www.caister.com/shigella

- Aquatic Biofilms: Ecology, Water Quality and Wastewater Treatment

Edited by: AM Romaní, H Guasch, MD Balaguer (2016)

"essential reference book" (Biotechnol. Agron. Soc. Environ.)

www.caister.com/aquaticbiofilms

- Alphaviruses: Current Biology

Edited by: S Mahalingam, L Herrero, B Herring (2016)

"up-to-date review of the field" (Aus. Vet. J.)

www.caister.com/alpha 